\title{
Epidemiology, risk factors and strategies for the prevention of global unintentional fatal drowning in people aged 50 years and older: a systematic review
}

\author{
Amy E Peden, ${ }^{1,2}$ Richard C Franklin, ${ }^{1,2}$ Ana Catarina Queiroga ${ }^{1,2,3}$
}

\begin{abstract}
- Additional material is published online only. To view please visit the journal online (http://dx.doi.org/10.1136/ injuryprev-2017-042351).

${ }^{1}$ Royal Life Saving Society Australia, Broadway, New South Wales, Australia ${ }^{2}$ College of Public Health, Medical and Veterinary Sciences, James Cook University, Townsville, Queensland, Australia

${ }^{3}$ EPIUnit - Instituto de Saúde Pública, Universidade do Porto, Porto, Portugal
\end{abstract}

Correspondence to Amy E Peden, Royal Life Saving Society - Australia, PO Box 558, Broadway, NSW 2007, Australia; apeden@rlssa.org.au

Received 2 February 2017 Revised 14 June 2017 Accepted 5 July 2017

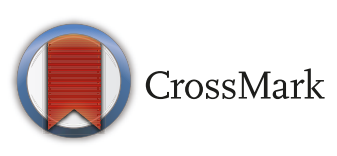

\begin{tabular}{|l|}
\hline To cite: Peden AE, \\
Franklin RC, \\
Queiroga AC.Inj Prev \\
Published Online First: [please \\
include Day Month Year]. \\
doi:10.1136/ \\
injuryprev-2017-042351
\end{tabular}

\begin{abstract}
Purpose Drowning is a global public health issue and prevention poses an ongoing challenge for all countries. Many nations are experiencing ageing populations, and little is known about the epidemiology, risk factors and prevention of drowning deaths among older people.

This paper reports on a systematic review of literature published on drowning among older people.

Methods A systematic literature review was undertaken using English-language, Portuguese-language and Spanish-language papers published between 1980 and 2015. The review explores gaps in the literature with a focus on the epidemiology, risk factors and strategies for the prevention of unintentional fatal drowning among people 50 years and over.

Results Thirty-eight papers were deemed relevant to the study design, including $18(47 \%)$ on epidemiology, $19(50 \%)$ on risk factors and 9 (24\%) on strategies for prevention. Risk factors identified included male gender, ethnicity, rurality and increasing age. Prevention strategies commonly proposed were education and wearing life jackets. Gaps identified in the published literature include a lack of consistency around age groupings used for epidemiological studies; a lack of consensus on risk factors; a lack of total population, country-level analysis; and the need for older age-specific prevention strategies that have been implemented and their effectiveness evaluated.

Conclusion This review identified drowning deaths among older people as a global issue. Further work is required to reduce drowning in this cohort. Highquality epidemiological studies identifying risk factors using standardised age groupings to allow for international comparisons are required, as are implementation and evaluation of older age-specific prevention strategies.
\end{abstract}

\section{INTRODUCTION}

As life expectancy increases, particularly in high-income countries (HICs), ${ }^{1}$ this brings with it new challenges, especially as many people are living healthy lives allowing them to enjoy a range of recreational pursuitsand undertake the activities of daily life. Drowning in older people is an often neglected ${ }^{2}$ yet growing problem across the globe as older people undertake aquatic activities to keep fit, recreate in and around water and move closer to aquatic locations in their retirement years. ${ }^{23}$ Drowning in older people is complicated by underlying medical conditions, ${ }^{45}$ impacted by lifestyle ${ }^{6}$ and likely to be preventable.
Globally, drowning is a significant cause of injury-related mortality. ${ }^{7}$ Although the circumstances and risk factors vary between HICs and low-income and middle-income countries (LMICs) due to socioeconomic factors and the differing use of waterways, be it daily living ${ }^{8}$ or recreational-related pursuits, ${ }^{9-11}$ prevention poses a challenge to all nations. Drowning rates vary by country, with low drowning rates in $\mathrm{HICs}^{2}{ }^{12}$ and increasingly high rates in LMICs. ${ }^{13} 14$

Children have been a major focus of drowning prevention ${ }^{15}{ }^{16}$; however, the strategies required to keep young children safe are not the same as are required for older children. These strategies are different again for adults and also possibly for older adults. As such, there is a need to better understand drowning risk factors and develop the evidence base for prevention. The 2005 statement defining drowning ${ }^{17}$ initiated much research, and since then there have been a number of systematic reviews highlighting the diversity of literature, the size of the problem, limited understanding of risk factors and the paucity of evidence-based prevention strategies. ${ }^{15} 161819$

Older people have been identified as being at a heightened risk of drowning, with drowning a leading injury mortality burden among older people in some nations. ${ }^{20}$ However, there is a lack of consensus about what 'old' is, with definitions ranging from 60 years to 75 years. ${ }^{21-23}$ Old age is sometimes linked to people becoming eligible for the pension in their country-commonly 65 years. ${ }^{22}$ An argument has been made that for some populations, such as countries in Africa and Indigenous populations where life expectancy is lower, the definition for old age should also be lowered. ${ }^{24}$ The World Health Organization's (WHO) Global Report on Drowning estimates 109746 people aged 45 years and over drowned in 2012, representing $29.5 \%$ of the global burden, with $81.6 \%$ occurring in LMICs. ${ }^{7}$ To capture as much research as possible and to explore potential differences between age groups considered to be 'older', the definition of 50 years and older has been used to define older people for the purposes of this systematic review.

\section{Aims}

With an ageing population and a lack of understanding around risk of unintentional fatal drowning among older people, there is a need to better understand the risk factors to develop more effective strategies for prevention. This systematic 
review of unintentional fatal drowning in older people aims to describe the epidemiology and risk factors, identify and critically analyse proposed strategies for prevention, and identify gaps in the published literature to date and propose priority areas for future research.

\section{METHODS}

This systematic literature review, using the Preferred Reporting Items for Systematic Reviews and Meta-Analyses (PRISMA) framework, ${ }^{25}$ explored literature published between 1980 and 2015 in English, Portuguese and Spanish languages. Portuguese-language and Spanish-language papers were screened by author ACQ, who is fluent in these languages. Databases used were Medline, PubMed, Scopus, ScienceDirect, PsycINFO, SPORTDiscus and Web of Science.

The internationally accepted definition of drowning was used $^{17}$; however, it should be noted that this definition was published in 2005 and papers published prior to 2005 may use other definitions. This study broadens the common definition of older age commencing at 60 or 65 years and uses 50 years and over. $^{24}$

A preliminary search of Medline was undertaken to identify relevant keywords contained in the titles, abstracts and subject descriptors. Initial search terms used were 'drown"' limited to English, Portuguese and Spanish languages, 'human' and a publish date range between 1 January 1980 and 31 December 2015. Search terms were then refined to include 'drown"' and 'older', 'elder', 'senior', 'geriatric', 'ageing', 'aged' and 'frail', as well as the equivalents in Portuguese and Spanish, such as 'afog"' and 'senior', 'idoso', 'idade' and 'ahog*', and 'anciano' and 'mayor', and were limited to peer-reviewed publications (online supplementary table S1). Five Spanish-language papers and zero Portuguese-language papers were identified. These were screened and one Spanish-language paper was included in the final review. ${ }^{26}$ However we note this paper was found by using the English keyword searches.

Papers under review were assessed according to the following inclusion criteria: (1) drowning was unintentional; (2) the literature included reference to people aged 50 years and/or older; and (3) the study included primary data. Exclusions included literature discussing drowning as a result of suicide or homicide, papers where unintentional drowning could not be separated from intentional drowning, or papers discussing non-fatal or hospitalization due to drowning.

The three authors (AEP, RCF, ACQ) assessed potentially eligible papers against the inclusion criteria. Each author reviewed a third of the papers at each step (title screen, abstract screen and full-text review). Where there was no consensus regarding inclusion or exclusion, a different second reviewer was used from among the remaining two authors. Review papers $(n=1)$ were excluded from this study. A hand-search technique was used to identify any additional primary data sources in the paper's references. A manual search was completed for all references retained for data extraction excluding grey literature.

Epidemiology papers that included rates per 100000 population are displayed in online supplementary table S3. Where rates were not expressed as per 100000 population (eg, per 10000 population), one author (AEP) manually converted these to rates per 100000 population. Rates in online supplementary table S3 are expressed as averages where the study period is more than 1 year (ie, the rate per annum was added and then divided by the number of years). Where papers included data by each individual year of the study period, these were manually converted into an annual average by one author (AEP). In online supplementary table S3 rate change within a study was calculated by comparing the rate for the first year of data presented with the rate for the last year of data presented for each age group.

Risk factors included in this study are those identified within a paper that had data (eg, Relative Risk (RR), percentage of deaths or rates) to support such statements. However we note that other risk factors for older people, not based on hard evidence, have been identified, including the role of pre-existing medical conditions, ${ }^{20}$ 2728 being alone, ${ }^{29}$ participating in recreational activities in the ocean $^{2830}$ and not wearing life jackets. ${ }^{31}$ There is a need to further explore risk factors for older people in a systematic way to clearly articulate whether they are risk factors or not, including an understanding of exposure. Where possible, rates in tables are based on exposure, ${ }^{32}$ not only population; however, there was a lack of information about exposure in the included studies.

Coding was used for data source in online supplementary table S3 for ease of presentation of information. Study country income level was derived from the gross national income per capita in $2015 .{ }^{33}$ The methodological quality of papers included in this review that proposed strategies for prevention was assessed using the National Health and Medical Research Council levels of evidence. ${ }^{34}$ Papers were assessed against six levels (I, II, III-1, III-2, III-3, IV) of strength of evidence ranging from level I (a systematic review of level II studies) to level IV (a cross-sectional study, a case series or expert opinion). ${ }^{34}$

\section{RESULTS}

Initial search results returned 5694 papers. After removing duplicates and undertaking title and abstract screening, 255 papers remained for full-text review (figure 1). After reviewing full texts, 217 papers were removed, leaving a library of 38 papers to be included in this systematic review (online supplementary table S2). Of the 38 papers, 18 (47.4\%) included epidemiological information, $19(50.0 \%)$ included information on risk factors and $9(23.7 \%)$ identified strategies for prevention.

\section{Epidemiology}

Of the 18 papers that examined the epidemiology of drowning deaths among those aged 50 years and over, seven (38.9\%) presented data for the $65+$ age group only (online supplementary table S3). Data were presented from 65 countries using 10 different data sources, with one paper ${ }^{20}$ providing data for 60 countries using the WHO Health Statistics and Information Services Mortality database. Twelve papers discussed data at a national level and six at a subnational level. The time periods covered by the studies ranged from 1 year ${ }^{35} 36$ to 15 years. $^{26}$ ${ }^{27}$ Data were presented on 34 HICs and 31 LMICs. The most commonly used data sources were death certificates $(50.0 \%)$, followed by coronial data and country-level statistics organisations (11.1\% respectively). Four studies (22.2\%) used the International Classification of Disease-10 (ICD-10), three (16.7\%) used ICD-9 and one (5.6\%) used both ICD-9 and ICD-10. For 10 studies $(55.6 \%)$ the coding source was unspecified or no ICD coding was used.

Rates presented ranged from a low of 0.2 per 100000 population for those aged 65 years and over in Turkey between 2006 and $2008,{ }^{20}$ to a high of 28.8 per 100000 population in people aged 80 years and older in Guangdong Province, China, between 2004 and $2005 .^{37}$

There were 27 countries with two studies, while France had three studies (two national) ${ }^{20} 38$ and the USA had eight studies (four national). ${ }^{20} 363940$ There were 27 papers that provided 


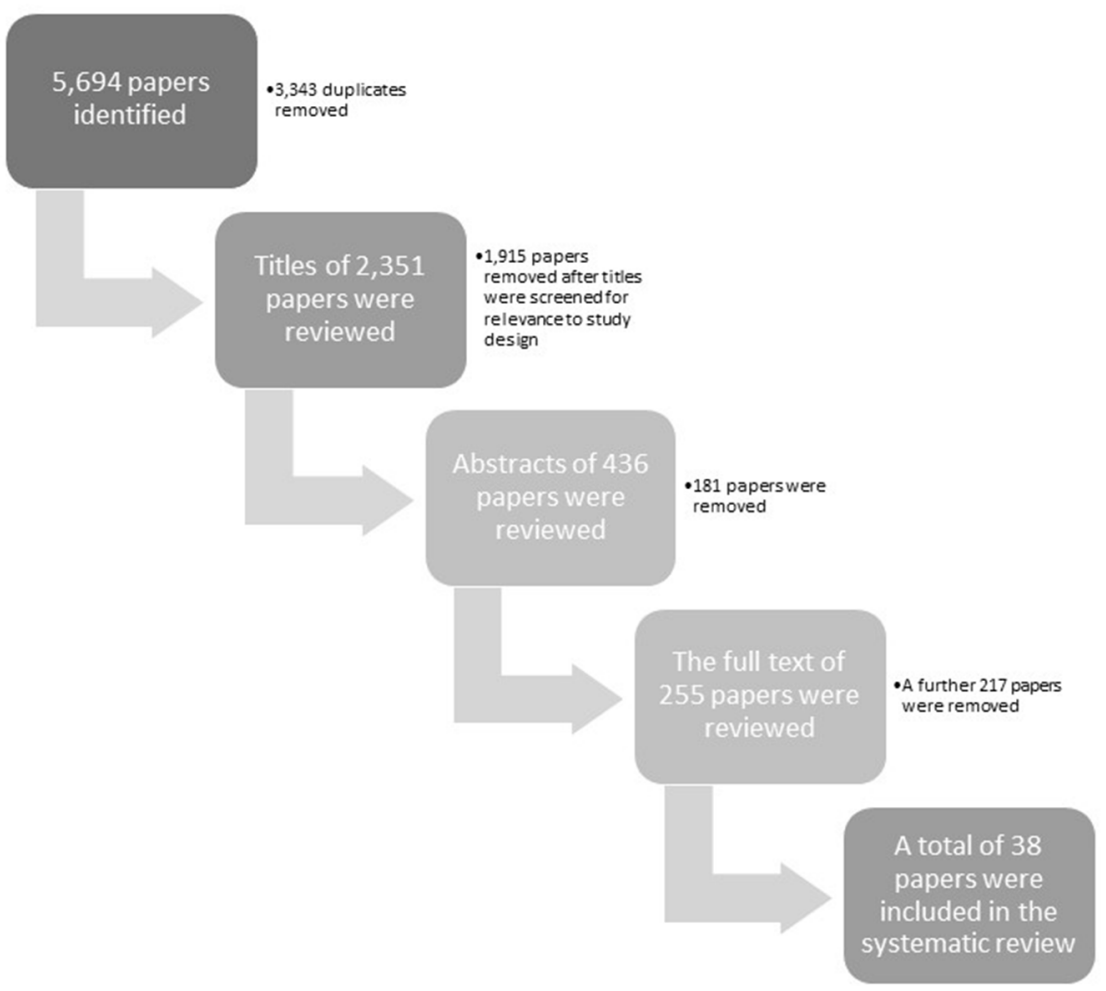

Figure 1 Modified Preferred Reporting Items for Systematic Reviews and Meta-Analyses (PRISMA) flow chart: process for extracting relevant papers $(n=38)$.

trends over time, 17 countries indicated decreasing rates and 10 papers showed increasing rates in the drowning rates of those aged $65+$. Sweden and Finland recorded the largest increases in the drowning rate of people aged $65+$ years at $8.1 \%$ and $5.8 \%$, respectively. ${ }^{38}$ In the 22 countries where there were two or more papers, and a comparison could be made (based on the same age groups), there were 14 countries with a decreasing fatal drowning rate, 6 with an increasing rate and 2 with no change. The changes over time between papers need to be considered with caution as most comparisons are from different data sources.

There was also some variation within age groups, for example, in $\mathrm{Cuba}^{26}$ between 1987 and 2002, drowning rates among people aged 50-59years increased, while decreasing among the 60+ years age group. Studies from the USA reported a decreasing drowning rate among people aged 50-54 years old between 1999 and $2001,,^{39}$ while among people aged $65+$ the rate was reported to have increased between 2000 and $2006 .^{40}$

\section{Risk factors}

Of the 19 studies investigating risk factors associated with unintentional fatal drowning in older people, $89 \%$ identified male gender, ${ }^{27}$ 29-32 $373941-50$ 26\% reported on ethnicity, ${ }^{27} 2939424816 \%$ on rurality, ${ }^{374142} 11 \%$ discussed increasing age ${ }^{3749}$ and 5\% discussed alcohol $^{31}$ (table 1).

Risk factor-related rates of drowning ranged from a low of 0.3 per 100000 people for men aged 65 years and older in watercraft-related fatal drownings in New York State, USA, ${ }^{48}$ to a high of 51.3 for Asian, African and Hispanic ethnicity rural-dwelling men aged 75 years and older in Ontario, Canada. ${ }^{42}$
Several papers provided data on the RR of older men drowning when compared with women. This risk ranged from a low of 1.0 times the risk for men 70-79years old in Guangdong Province, China, ${ }^{37}$ to a high of 19.7 times the risk among men aged 85 years and older in Denmark. ${ }^{44}$ One study found women aged 65 years and older were at 1.5 times the risk of fatal drowning when exposed to swimming, fishing or rock fishing, and 1.6 times the risk when exposed via swimming when compared with men of the same age ${ }^{32}$ (online supplementary table S4).

Ethnicity was also identified as a risk factor, with AfricanAmerican men aged 65 years and older being 2.3 times more likely than white men to drown as a result of watercraft-related incidents in New York State. ${ }^{48}$ Conversely, when non-bathtub drowning deaths in New York State are examined, white men aged 65 years and older were found to be 1.5 times more likely to drown when compared with African-American men ${ }^{29}$ (online supplementary table S4).

Common groupings of risk factors identified through this review included male gender with ethnicity ${ }^{42} 4851$ and male gender with rurality ${ }^{374142}$ (table 1).

\section{Strategies for prevention}

Nine papers identified through this systematic review discussed strategies for the prevention of unintentional fatal drowning among older people (table 2). Three papers ${ }^{52-54}$ explored the effectiveness of prevention strategies, all of which concerned life jacket wear regulations. One study, using population-based data from the Australian state of Victoria, found that compulsory life jacket wear regulations did not cause a significant reduction in fatal drowning among those aged $60+$, as it had in other age groups. ${ }^{52}$ Conversely, a second 
Table 1 Summary of relevant papers discussing risk factors for fatal drowning among people aged 50 years and older $(\mathrm{n}=19)$

\begin{tabular}{|c|c|c|c|c|}
\hline Country (area of country) & Population & Risk factors & Relevant age group & Reference \\
\hline \multirow[t]{4}{*}{ Australia (New South Wales) } & \multirow[t]{4}{*}{ Residents aged $16+$} & Men & $65+$ & \multirow[t]{4}{*}{ Mitchell et $a l^{\beta 2}$} \\
\hline & & Men exposed — being in or near water & $65+$ & \\
\hline & & $\begin{array}{l}\text { Women exposed — swimming, boating, rock } \\
\text { fishing }\end{array}$ & $65+$ & \\
\hline & & Women exposed — swimming & $65+$ & \\
\hline Canada (Ontario) & All & Male rural residents & $55+$ & Fralick et al ${ }^{41}$ \\
\hline Canada (Ontario) & All except bathtubs & $\begin{array}{l}\text { Asian, African and Hispanic ethnicity rural- } \\
\text { dwelling men }\end{array}$ & $55+$ & Gallinger et al ${ }^{42}$ \\
\hline \multirow[t]{4}{*}{ China (Guangdong Province) } & \multirow[t]{4}{*}{ All } & Men & $50-59$ & \multirow[t]{4}{*}{ Ma et $a l^{\beta 7}$} \\
\hline & & Rural-dwelling men & $60-69$ & \\
\hline & & Rural-dwelling women & $70-79$ & \\
\hline & & Increasing age & $80+$ & \\
\hline China (Guangxi Province) & All & Men & $50+$ & Yang et $a l^{43}$ \\
\hline Denmark & All & Men & $55+$ & Steensberg $^{44}$ \\
\hline Finland & All & Non-boating & $55+$ & Lunetta et $a^{82}$ \\
\hline Japan & All & Bathtubs and bathing & $65+$ & Lin et $a l^{20}$ \\
\hline \multirow[t]{2}{*}{ New Zealand } & \multirow[t]{2}{*}{ All } & Power boating men & $55-59$ & \multirow[t]{2}{*}{ Croft and Button ${ }^{30}$} \\
\hline & & Non-powered boating men & $60-64$ & \\
\hline \multirow[t]{2}{*}{ Norway (Western Norway) } & \multirow[t]{2}{*}{ All } & Men & $60+$ & \multirow[t]{2}{*}{ Eilertsen et $a l^{\beta 1}$} \\
\hline & & Alcohol & $60+$ & \\
\hline Poland & All except watercraft & Men & $60-74$ & Halik et $a d^{45}$ \\
\hline Turkey & $\begin{array}{l}\text { All (using online search engines } \\
\text { and newspapers) }\end{array}$ & Men & $50+$ & Turgut and Turgut ${ }^{46}$ \\
\hline USA & All & Falls & $65+$ & Lin et $a l^{20}$ \\
\hline \multirow[t]{3}{*}{ USA } & \multirow[t]{3}{*}{ All } & Black people & $50-54$ & \multirow[t]{3}{*}{ Hastings et al ${ }^{\beta 9}$} \\
\hline & & Men & $50-54$ & \\
\hline & & Black men & $50-54$ & \\
\hline USA (California) & All & Men & $85+$ & Saunders et $a l^{47}$ \\
\hline \multirow[t]{2}{*}{ USA (New York State) } & \multirow[t]{2}{*}{ Non-bathtub drowning deaths } & Men & $65+$ & \multirow[t]{2}{*}{ Browne et a ${ }^{29}$} \\
\hline & & White men & $65+$ & \\
\hline \multirow[t]{2}{*}{ USA (New York State) } & \multirow{2}{*}{$\begin{array}{l}\text { Watercraft-related drowning } \\
\text { deaths }\end{array}$} & Men & $65+$ & \multirow[t]{2}{*}{ Browne et a ${ }^{48}$} \\
\hline & & African-American men & $65+$ & \\
\hline \multirow[t]{2}{*}{ USA (Los Angeles County) } & \multirow[t]{2}{*}{ All } & Men & $50+$ & \multirow[t]{2}{*}{$0^{\prime}$ Carroll et a ${ }^{49}$} \\
\hline & & Increasing age & $70+$ & \\
\hline \multirow{3}{*}{$\begin{array}{l}\text { USA (Washington State - three } \\
\text { counties) }\end{array}$} & \multirow[t]{3}{*}{ Residents } & Men & $65+$ & \multirow[t]{3}{*}{ Quan and Cummings ${ }^{27}$} \\
\hline & & Asian people & $65+$ & \\
\hline & & Body of water outside & $65+$ & \\
\hline \multirow[t]{2}{*}{ USA (Wisconsin) } & All (1984-1988) & Men & $65+$ & Cox et $\left.a\right|^{50}$ \\
\hline & All (1994-1998) & Men & $65+$ & \\
\hline
\end{tabular}

study reported adult life jacket use was lowest among those aged 65 years and older. ${ }^{54}$ A third, using observational studies, found a $56 \%$ increase life jacket wear among those aged $60+$ in small power vessels as a result of legislation. ${ }^{53}$

Of the six papers proposing prevention strategies, education was discussed in four papers ${ }^{28} 444955$ (66.7\%), including flood safety awareness programmes ${ }^{55}$; education of medical doctors, nurses and nursing home staff to pay attention to existing diseases that increase drowning risk, including dementia ${ }^{44}$; advice to those with pre-existing health conditions to limit aquatic activities to areas with lifeguarding services or where companions are trained in cardiopulmonary resuscitation; and physicians to educate elderly patients on the dangers of falls into bathtubs. Other studies proposed a range of strategies, including further research, reskilling of the at-risk population ${ }^{2}$ and improvements to watercourses through engineering, ${ }^{56}$ among others. Evidence used in papers proposing prevention strategies were low, with all $(100.0 \%)$ being classified as level IV-expert opinion.

\section{DISCUSSION}

This systematic review identified 38 studies detailing the epidemiology, risk factors and strategies for the prevention of unintentional fatal drowning among older people aged 50 years and older. A key factor impacting the ability to extract relevant studies for this review was the lack of consistent age group bands. Despite both the United Nations ${ }^{57}$ and the $\mathrm{WHO}^{58}$ proposing standard international age classifications, and support for age groupings to be mid-decade to mid-decade or in 5-year age groups, ${ }^{59}$ there was a wide variety of age group bands used. We recommend all studies should, as a minimum, have the $65+$ years age group clearly identified. If data allow, the $65+$ age group should then be broken down further. This allows for comparison between countries and within countries, as well as identify age-specific risk factors, enhancing prevention efforts. 
Table 2 Relevant papers discussing proposed prevention strategies for unintentional fatal drowning among people aged 50years and older $(\mathrm{n}=9)$

\begin{tabular}{|c|c|c|c|}
\hline Country (area of country) & Prevention strategies & Level of evidence & Reference \\
\hline Australia (Victoria) & $\begin{array}{l}\text { Compulsory personal flotation device (PFD) wearing regulations. } \\
\text { The introduction of legislation requiring mandatory life jacket wear did not } \\
\text { cause a significant reduction in fatal drowning among those aged } 60+\text { as it } \\
\text { did in other age groups. }\end{array}$ & $\begin{array}{l}\text { IV } \\
\text { Population-based study }\end{array}$ & Bugeja et $\left.a\right|^{52}$ \\
\hline Australia (Victoria) & $\begin{array}{l}\text { Mandatory PFD wearing regulations for small (hull length } \leq 4.8 \mathrm{~m} \text { ) power } \\
\text { recreational vessels. } \\
56 \% \text { increase in life jacket wear among } 60+\text { in small power vessels due to } \\
\text { legislation (from } 4 \% \text { to } 60 \% \text { ). }\end{array}$ & $\begin{array}{l}\text { III-3 (observational studies at } 42 \\
\text { boat ramps) }\end{array}$ & Cassell and Newstead ${ }^{53}$ \\
\hline USA (Washington State) & $\begin{array}{l}\text { Life jacket use is mandated for people being towed by boats (such as } \\
\text { water skiers), people on personal watercrafts and children on boats. } \\
\text { Observational studies found that } 18.3 \% \text { of those aged } 65 \text { years and over } \\
\text { wore a life jacket. (RR } 0.8 \text { (Cl } 0.69 \text { to } 1.0 \text { ) bivariate model, } 1.1 \text { (Cl } 0.84 \text { to } \\
\text { 1.5) multivariable model). Among adult boaters, life jacket use was lowest } \\
\text { among those aged } 65 \text { years and over. }\end{array}$ & $\begin{array}{l}\text { III-3 (observational studies at } 33 \\
\text { sites) }\end{array}$ & Chung et $a I^{54}$ \\
\hline Country (area of country) & Proposed prevention strategies & Level of evidence & Reference \\
\hline Australia & Education: flood safety awareness programmes targeting those at high risk & $\begin{array}{l}\text { IV } \\
\text { Expert opinion and case series }\end{array}$ & Fitzgerald et $a f^{55}$ \\
\hline Australia & $\begin{array}{l}\text { Reskilling } \\
\text { Increased safety systems in a diverse range of locations } \\
\text { Research }\end{array}$ & $\begin{array}{l}\text { IV } \\
\text { Population-based study }\end{array}$ & Franklin et $a l^{2}$ \\
\hline Denmark & $\begin{array}{l}\text { Education: medical doctors, nurses and nursing home staff to pay more } \\
\text { attention to the risk of existing disease, especially those suffering from } \\
\text { dementia and confusion }\end{array}$ & $\begin{array}{l}\text { IV } \\
\text { Expert opinion and case series }\end{array}$ & Steensberg $^{44}$ \\
\hline Iran (Northern Iran) & $\begin{array}{l}\text { Education: strongly worded advice for those with pre-existing health } \\
\text { conditions to limit swimming and other activities to areas where } \\
\text { lifeguarding services are provided and/or where companions are trained to } \\
\text { provide cardiopulmonary resuscitation }\end{array}$ & $\begin{array}{l}\text { IV } \\
\text { Population-based study }\end{array}$ & Kiakalayeh et $\left.a\right|^{28}$ \\
\hline $\begin{array}{l}\text { Japan (Tokyo and Saga } \\
\text { Prefectures) }\end{array}$ & $\begin{array}{l}\text { Implement measures aimed at preventing falls and drowning in outdoor } \\
\text { environments } \\
\text { Engineering: improvements to watercourses }\end{array}$ & $\begin{array}{l}\text { IV } \\
\text { Expert opinion and case series }\end{array}$ & Kibayashi et $a l^{56}$ \\
\hline USA (Los Angeles County) & $\begin{array}{l}\text { Education: physicians caring for elderly patients might advise them of the } \\
\text { danger of bathtub falls } \\
\text { Research: more needs to be learnt about the context in which } \\
\text { swimming pool and bathtub drownings occur among the elderly }\end{array}$ & $\begin{array}{l}\text { IV } \\
\text { Population-based study }\end{array}$ & $0^{\prime}$ Carroll et al ${ }^{49}$ \\
\hline
\end{tabular}

\section{Epidemiology}

Sixty-five countries were covered by the epidemiological studies included in this review, including 31 LMICs (of which 28 were covered by one study ${ }^{20}$ ). While increasing research on drowning risk factors is being undertaken in LMICs, much of this work focuses on children, ${ }^{6061}$ with little known about drowning risk among the elderly. Therefore, there is a need for further total population-based research on this issue among LMICs, which is made challenging due to a lack of deaths data, data quality issues $^{7}$ and the inability to separate different aquatic locations using ICD coding. ${ }^{15} 20$

Few papers provided breakdowns of age, with many countries presenting data on the $65+$ years age group only $(87.7 \%$ of all countries covered by the studies in this review). Where this information was present, there was variation between the age groups, with studies examining drowning in 5-year age bands from 50 to 54 to $85+,{ }^{2}$ a study that stopped at the 50-54 years age group, ${ }^{39}$ a study examining 50-59, 60-69 and 70+ years, ${ }^{49}$ and a study with older age groups of 55-64, 65-74 and $75+,{ }^{36}$ among other variations. The drowning rate by age group does vary for those over 50years, 2637394649 and thus greater differentiation of age is required to understand the risks and develop prevention strategies. It should be noted that high rates may not equate to high frequencies of drowning, and this must be considered when interpreting the results of epidemiological studies.

Where studies spanned more than 1 year, five papers provided data on trends over time with respect to drowning rates. ${ }^{2638-4046}$
It was also challenging to compare rate change within a country. The USA was the only country where this analysis was possible, with the drowning rate among people 50-54 years old in 19992001 reported to be decreasing ${ }^{39}$ and the rate among those $65+$ increasing between 2000 and 2006 . $^{40}$

While all studies included in this systematic review were those that included epidemiological data on unintentional fatal drowning only, when examining trends, the inclusion/exclusion criteria of the study, as well as the ICD edition (ICD-9, ICD-10, both), must be considered. The reporting of unintentional drowning in many nations is currently limited to external cause codes W65-74, which under-reports drowning deaths, particularly those as a result of water transportation and disaster. ${ }^{62}$ Any changes in drowning rates must also be considered with caution as there may be other factors influencing fluctuating drowning rates, such as improvements in data collection and reporting of drowning cases, changes in coding mechanism and/or changes in the inclusion/exclusion criteria of a particular study.

There is a need for further research that uses population-level data and is stratified by consistent age group bands. This would allow for further comparison between countries and within and between regions, which also allows for the surveillance of trends in drowning data over time as well as the identification of effective drowning prevention strategies. ${ }^{15}$ 


\section{Risk factors}

Over the past two decades, the risk factors for drowning have become increasingly well understood ${ }^{63}$; however, further research is required into unintentional drowning risk factors among older people aged 50 years and above. Of the 19 studies on risk factors included in this review, 16 risk factors were identified. There was little consensus beyond the common finding that older men are at an increased risk of drowning compared with older women. Men of all ages have been identified as being at an increased risk of drowning in many countries ${ }^{126465}$; however, it remains to be seen whether drowning prevention strategies aimed at men of all ages will specifically work in addressing drowning among older men.

One study ${ }^{20}$ identified falls as a factor increasing the risk of drowning among older people in the USA. Falls into water is a commonly reported activity prior to drowning for older people in many countries ${ }^{920} 27$ and categories of aquatic location. ${ }^{12}$ ${ }^{20}$ However older people are known to be at an increased risk of falls ${ }^{5666}$ due to age-related factors such as loss of muscle strength, balance and bone density. ${ }^{4}$ Therefore, preventing fatal drownings as a result of falls into water needs further research. For example, is it more effective to implement strategies to reduce falls in older people in general, or are older people at an increased risk of falling into water specifically?

There was only one paper ${ }^{32}$ that used exposure information rather than just population to explore risk. Further research in the form of exposure studies may assist in answering questions around risk. Implementation and evaluation of prevention strategies may also assist in determining if falls prevention strategies will be more effective in reducing fall-related drowning among older people, as opposed to drowning-specific prevention strategies, such as learning to swim and increasing mobility to aid with exiting the water.

Exposure studies would also be beneficial across the spectrum of risk factors identified for drowning among older people to determine true risk. For example, pre-existing medical conditions such as dementia may be a risk factor for drowning among the elderly; however, data on the prevalence of the condition within the general population, compared with the cohort who drown, are required.

A significant gap in the published literature was the lack of $\mathrm{RR}$ analysis, with the authors of this systematic review having to calculate the RR themselves where possible. The use of analytic studies to determine, in this case, RR allows for a better understanding of the impact of a risk factor. We note, however, that only one of the studies ${ }^{32}$ had a denominator that included information about exposure. As with the need for further population-level studies, so too is there a need for RR to be calculated to strengthen the evidence-based identification of risk factors, as well as undertaking regression studies to better understand the relationships among variables.

\section{Strategies for prevention}

Many studies excluded from this systematic review discussed strategies for the prevention of drowning generally, but did not discuss stratagems specific to the issue of drowning among older people. ${ }^{264367}$ All strategies for prevention identified through a review of the literature are broad in nature, aimed at older or elderly people in general without identifying a specific age group more at risk nor the effectiveness for these age groups.

Similarly, many studies covered epidemiology and risk factors but did not go further and apply those findings to the proposal of evidence-based strategies for prevention; a total of 18 studies examined the epidemiology of drowning among older people, and 19 identified risk factors; however, only nine studies proposed prevention strategies, with only a third of those having been evaluated. For proposed strategies not yet implemented, the evidence supporting such recommendations was low for all studies (level IV-expert opinion).

There is a lack of research to determine if older people benefit from the same type of prevention strategies as younger people or if they need specific strategies more relevant to the risk factors experienced prior to drowning. Achievements in drowning prevention to date suggest site-specific and age-specific stratagems that address known risk factors will be more effective in reducing loss of life. ${ }^{1568}$

Exposure brings with it its own challenges for prevention. Participation in aquatics can be an important low-impact activity promoting physical health in older people ${ }^{3}$ and providing opportunities for social interaction, thus improving quality of life. ${ }^{6970}$ Older people may also bring with them knowledge and experience in aquatic-related pursuits, such as boating, ${ }^{71}$ thereby reducing the risk of a fatal incident. However, further research is required to determine if there is a link between experience and reduced drowning risk.

\section{Additional research gaps}

A number of other issues were identified when examining research published on unintentional fatal drowning among older people. Several studies had to be excluded from this systematic review such as those that discussed drowning by age group using graphs without discussing actual rates or proportions in the text, ${ }^{72} 73$ those that examined the issue of drowning without stratifying by age group ${ }^{74}$ and those that did not separate intentional and unintentional deaths. ${ }^{7677}$ As has been identified in other studies, data on location and activity prior to drowning were not consistently presented in the studies included in this review. Many countries were hampered by a lack of detail within the ICD external cause codes. ${ }^{15} 20$ This lack of detail on causal factors leading to drowning hampers prevention efforts.

\section{Limitations}

- Discussion of drowning deaths among this age group might be hidden in other broader papers discussing drowning among a population level or as a result of a particular activity or location; therefore older people will be a subset rather than the focus of the paper.

- Only those papers published in English, Portuguese and Spanish were included in this review. We may therefore have not included all papers published on this topic if published in other languages.

- This systematic review was of peer-reviewed academic articles. There may be other high-quality studies in non-peerreviewed publications.

- The data used in this study are extracted from the studies, not the raw data. Therefore we are unable to verify the accuracy of the data, beyond what is presented in the studies included in this systematic review (eg, the potential misclassification of intentional vs unintentional drowning deaths).

\section{CONCLUSION}

Drowning in older people is an ongoing problem and, for some countries, an increasing challenge. Little is known about the risk factors nor effective prevention stratagems. In light of inadequate knowledge in this space, we can only support current prevention strategies being used and encourage 
further work that elucidates effective interventions. With an ageing population, drowning in older people is likely to be an area of increasing concern. Drowning among those aged 45 years and over accounts for an estimated 109746 lives lost globally each year; therefore, any achievements in drowning prevention are likely to have a significant impact. However, a lack of action in this area may prove to be an impediment to overall reductions in drowning mortality and increases in life expectancy.

It is vital that further country-level, total population epidemiological studies into the issue of drowning among older people be undertaken, including the use of exposure studies to determine risk factors for both HIC and LMICs. Evidencebased strategies for prevention that are implemented and evaluated will have the greatest likelihood of being successful in reducing drowning among this age group.

\section{What is already known on the subject}

- Globally, populations are ageing.

- Little is known about drowning among older people, particularly older people in low-income and middle-income countries (LMICS).

\section{What this study adds}

- Rates of drowning among older people range from a low of 0.2 for people 65+ years old in Turkey from 2006 to 2008, to a high of 28.8 in people aged 80 years and over in Guangdong Province, China between 2004 and 2005.

- Little research focuses on drowning in older people outside the age grouping of $65+$ years.

- Risk factors for older people drowning include male gender, ethnicity, rurality and increasing age, although there was a lack of consensus.

- Gaps identified in the published literature include the need for consistent age groupings to be used in analysis, and further population-level analyses (particularly in LMICs) and evidencebased strategies for prevention, tailored specifically to older people, which have been implemented and evaluated.

Twitter Follow Amy Peden at @amyepeden, follow Richard Franklin at @ Franklin_R_C, follow Ana Catarina Queiroga at @ac_queiroga and follow Royal Life Saving Society - Australia at @royallifesaving

Acknowledgements This research is supported by the Royal Life Saving Society - Australia to aid in the reduction of drowning. Research at the Royal Life Saving Society - Australia is supported by the Australian Government.

Contributors AEP, RCF and ACQ conceptualised and designed the study. ACQ conducted the literature searches, and AEP, RCF and ACQ reviewed titles, abstracts and full text equally. ACQ reviewed all papers in languages other than English AEP conducted the analysis, drafted the initial manuscript and approved the final manuscript as submitted. RCF reviewed and revised the manuscript and approved the final manuscript. ACQ reviewed and revised the manuscript and approved the final manuscript as submitted.

Funding This research received no specific grant from any funding agency in the public, commercial or not-for-profit sectors.

Competing interests None declared.

Provenance and peer review Not commissioned; externally peer reviewed.

(c) Article author(s) (or their employer(s) unless otherwise stated in the text of the article) 2017. All rights reserved. No commercial use is permitted unless otherwise expressly granted.

\section{REFERENCES}

1 Audit Commission. Don't stop me now: Preparing for an ageing population. London, 2008.

2 Franklin RC, Scarr JP, Pearn JH. Reducing drowning deaths: the continued challenge of immersion fatalities in Australia. Med J Aust 2010;192:123-6.

3 Sherlock LA, Guyton Hornsby Jnr W, Rye J. The physiological effects of aquatic exercise on cognitive function in the Aging Population. IJARE 2013;7:266-78.

4 Mahony AJ, Peden AE, Franklin RC, et al. Unintentional drowning in older people: an assessment of the role of preexisting medical conditions. Healthy Aging Research 2017:1:e7

5 Papadodima SA, Sakelliadis El, Kotretsos PS, et al. Cardiovascular disease and drowning: autopsy and laboratory findings. Hellenic J Cardiol 2007:48:198-205.

6 Lasbeur L, Thélot B. Fatal home and leisure injuries in mainland France, 2000-2006. Bulletin Epidemiologique Hebdomadaire 2010;8:65-9.

7 World Health Organization. Global Report on Drowning: preventing a leading killer. Geneva: World Health Organization, 2014

8 Rahman A, Shafinaz S, Linnan M, et al. Community perception of childhood drowning and its prevention measures in Rural Bangladesh: a Qualitative study. Aust J Rural Health 2008;16:176-80.

9 Royal Life Saving Society - Australia. Royal Life Saving National Drowning Report. 2016, 2016

10 Rouse A. Recreational drowning deaths in the south west of England. West Eng/ Med J 1991;106:65-6.

11 Wyatt JP, Tomlinson GS, Busuttil A. Resuscitation of drowning victims in south-east Scotland. Resuscitation 1999;41:101-4.

12 Peden AE, Franklin RC, Leggat PA. The Hidden Tragedy of Rivers: a Decade of Unintentional Fatal Drowning in Australia. PLoS One 2016;11:e0160709.

13 Prameprart M, Lim A, Tongkumchum P. Modeling unintentional drowning mortality rates in Thailand, 2000-2009. Asia Pac J Public Health 2015;27:NP2471-NP2479.

14 Gerdmongkolgan S, Ekchaloemkiet S, Siriphanich T. Policy advocacy on child drowning prevention in Thailand. Injury Prevention 2010;16:A43.

15 Peden AE, Franklin RC, Leggat PA. Fatal river drowning: the identification of research gaps through a systematic literature review. Inj Prev 2016:22:202-9.

16 Wallis BA, Watt K, Franklin RC, et al. Interventions associated with drowning prevention in children and adolescents: systematic literature review. Inj Prev $2015 ; 21$.

17 van Beeck EF, Branche CM, Szpilman D, et al. A new definition of drowning: towards documentation and prevention of a global public health problem. Bull World Health Organ 2005;83:853-6.

18 Leavy JE, Crawford G, Portsmouth L, et al. Recreational drowning Prevention Interventions for adults, 1990-2012: a review. J Community Health 2015;40:725-35.

19 Crawford G, Leavy J, Portsmouth L, et al. Development of a systematic review of Public Health Interventions to prevent Children drowning. Open J Prev Med 2014;04:100-6.

20 Lin CY, Wang YF, Lu TH, et al. Unintentional drowning mortality, by age and body of water: an analysis of 60 countries. Inj Prev 2015;21:e43-50.

21 Thane P. The muddled history of retiring at 60 and 65 . New Society 1978:45:234-6.

22 Roebuck J. When does "Old Age Begin?": The Evolution Of The English Definition. J Soc Hist 1979:12:416-28.

23 Orimo H. [Reviewing the definition of elderly]. Nihon Ronen Igakkai Zasshi 2006:43:27-34

24 World Health Organization. Proposed working definition of an older person in Africa for the MDS project. 2002, 2017. http://www.who.int/healthinfo/survey/ ageingdefnolder/en/ (accessed 9 Jan 2017).

25 Moher D, Liberati A, Tetzlaff J, et al. Preferred reporting items for systematic reviews and meta-analyses: the PRISMA statement. BMJ 2009:339:b2535.

26 Hernández Sánchez M, García Roche R, Valdés Lazo F, et al. Accidental drowning and submersion: mortality in Cuba. Revista Cubana de Higiene y Epidemiologia 2005;43:1987-2002.

27 Quan L, Cummings P. Characteristics of drowning by different age groups. Inj Prev 2003;9:163-8

28 Kiakalayeh AD, Mohammadi R, Ekman DS, et al. Unintentional drowning in Northern Iran: a population-based study. Accid Anal Prev 2008;40:1977-81.

29 Browne ML, Lewis-Michl EL, Stark AD. Unintentional drownings among New York State residents, 1988-1994. Public Health Rep 2003;118:448-58.

30 Croft JL, Button C. Interacting factors associated with adult Male Drowning in New ZealandPLOS ONE. PLOS OneElectronic Resource 2015;10:e0130545. Research Support, Non-U.S. Gov't.

31 Eilertsen $\mathrm{HH}$, Lilleng PK, Mæhle BO, et al. Unnatural death in the elderly : A forensic study from western norway. Forensic Sci Med Pathol 2007:3:23-31.

32 Mitchell RJ, Williamson AM, Olivier J. Estimates of drowning morbidity and mortality adjusted for exposure to risk. Inj Prev 2010;16:261-6.

33 The World Bank. GNI per capita, Atlas method (current US\$), 2016. http://data. worldbank.org/indicator/NY.GNP.PCAP.CD?order=wbapi_data_value_2014+wbapi_ data_value+wbapi data_value-last\&sort=desc (accessed 31 Dec 2016).

34 Australian Government National Health and Medical Research Council (NHMRC). NHMRC additional levels of evidence and grades for recommendations for developers of guidelines, 2005. 
35 Mecrow TS, Rahman A, Mashreky SR, et al. Willingness to administer mouth-to-mouth ventilation in a first response program in rural Bangladesh. BMC Int Health Hum Rights 2015;15:19.

36 Vyrostek SB, Annest JL, Ryan GW. Surveillance for fatal and nonfatal injuries--United States, 2001. MMWR Surveill Summ 2004;53:1-57.

37 Ma W, Xu Y, Xu X. Is drowning a serious public health problem in Guangdong Province, People's Republic of China?--results from a retrospective population-based survey, 2004-2005. Int J Inj Contr Saf Promot 2010;17:103-10.

38 Petridou ET, Dikalioti SK, Dessypris N, et al. The evolution of unintentional injury mortality among elderly in Europe. J Aging Health 2008;20:159-82.

39 Hastings DW, Zahran S, Cable S. Drowning in inequalities: swimming and social justice. J Black Stud 2006;36:894-917.

$40 \mathrm{Hu}$ G, Baker SP. Recent increases in fatal and non-fatal injury among people aged 65 years and over in the USA. Inj Prev 2010;16:26-30.

41 Fralick M, Gallinger ZR, Hwang SW. Differences in drowning rates between rural and non-rural residents of Ontario. . Canada: International Journal of Aquatic Research and Education, 2013:7. 332-43

42 Gallinger ZR, Fralick M, Hwang SW. Ethnic differences in drowning rates in Ontario, Canada. J Immigr Minor Health 2015;17:1436-43.

43 Yang L, Lam LT, Liu Y, et al. Epidemiological profile of mortality due to injuries in three cities in the Guangxi Province, China. Accid Anal Prev 2005;37:137-41.

44 Steensberg J. Epidemiology of accidental drowning in Denmark 1989-1993. Accid Anal Prev 1998;30:755-62.

45 Halik R, Poznańska A, Seroka W, et al. Accidental drownings in Poland in 2000-2012. Przegl Epidemiol 2014;68:493591-4.

46 Turgut A, Turgut T. A population-based study on deaths by drowning incidents in Turkey. Int J Inj Contr Saf Promot 2014;21:61-7.

47 Saunders LD, Green M, Doebbert G, et al. Mortality from unintentional injuries in California, 1985. West J Med 1989;150:478-83.

48 Browne ML, Lewis-Michl EL, Stark AD. Watercraft-related drownings among New York State residents, 1988-1994. Public Health Rep 2003;118:459-63.

49 O'Carroll PW, Alkon E, Weiss B. Drowning mortality in Los Angeles County, 1976 to 1984. JAMA 1988;260:380-3.

50 Cox E, Tseng DS, Powell I. Trends in falls, poisoning, drowning, and Burns Wisconsin: 1986-1996. WMJ 2001;100:39-42.

51 Nasrullah M, Muazzam S. Drowning mortality in the United States, 1999-2006. J Community Health 2011;36:69-75.

52 Bugeja L, Cassell E, Brodie LR, et al. Effectiveness of the 2005 compulsory personal flotation device (PFD) wearing regulations in reducing drowning deaths among recreational boaters in Victoria, Australia. Inj Prev 2014;20:387-92. Research Support, Non-U.S. Gov't.

53 Cassell E, Newstead S. Did compulsory wear regulations increase personal flotation device (PFD) use by boaters in small power recreational vessels? A before-after observational study conducted in Victoria, Australia. Inj Prev 2015;21:15-22. Research Support, Non-U.S. Gov't.

54 Chung C, Quan L, Bennett E, et al. Informing policy on open water drowning prevention: an observational survey of life jacket use in Washington State. Inj Prev 2014;20:238-43.

55 FitzGerald G, Du W, Jamal A, et al. Flood fatalities in Contemporary Australia (19972008). Emerg Med Australas 2010;22:180-6.

56 Kibayashi K, Shimada R, Nakao K. Temporal and regional variations in accidental deaths of elderly people in Japan. Med Sci Law 2013;53:172-6.
57 World Health Organization. Provisional guidelines on Standard International Age Classifications: World Health Organization, 1982.

58 Ahmad OB, Boschi-Pinto C, Lopez AD, et al. Age Standardization of Rates: a New WHO Standard: World Health Organization, 2001.

59 Reijneveld SA. Age in epidemiological analysis. J Epidemiol Community Health 2003;57:397.

60 Mecrow TS, Linnan M, Rahman A, et al. Does teaching children to swim increase exposure to water or risk-taking when in the water? emerging evidence from Bangladesh. Inj Prev 2015;21:185-8.

61 Jagnoor J, Bassani DG, Keay L, et al. Unintentional injury deaths among children younger than 5 years of age in India: a nationally representative study. Inj Prev 2011;17:151-5.

62 Passmore JW, Smith JO, Clapperton A. True burden of drowning: compiling data to meet the new definition. Int J Inj Contr Saf Promot 2007;14:1-3.

63 Smith GS, Barss P. Unintentional injuries in developing countries: the epidemiology of a neglected problem. Epidemiol Rev 1991;13:228-66. Research Support, Non-U.S. Gov't, Research Support, U.S. Gov't, P.H.S., Review..

64 Howland J, Hingson R, Mangione TW, et al. Why are most drowning victims men? sex differences in aquatic skills and behaviors. Am J Public Health 1996;86:93-6.

65 Duraković Z, Duraković MM, Skavić J, et al. Unexpected sudden death due to recreational swimming and diving in men in Croatia in a 14-year period. Coll Antropol 2012;36:641-5.

66 Guse CE, Porinsky R. Risk factors associated with hospitalization for unintentional falls: wisconsin hospital discharge data for patients aged 65 and over. WMJ 2003; 102:37-42.

67 Warner M, Smith GS, Langley JD. Drowning and alcohol in New Zealand: what do the coroner's files tell us? Aust N Z J Public Health 2000;24:387-90. Research Support, U.S. Gov't, P.H.S.

68 Bugeja L, Franklin RC. An analysis of stratagems to reduce drowning deaths of young children in private swimming pools and spas in Victoria, Australia. Int J Inj Contr Saf Promot 2013;20:1-13.

69 Sato D, Kaneda K, Wakabayashi H, Nomura T, et al. The water exercise improves health-related quality of life of frail elderly people at day service facility. Qual Life Res 2007;16:1577-85.

70 Lim K, Taylor L, Kim Lim LT. Factors associated with physical activity among older people--a population-based study. Prev Med 2005;40:33-40.

71 Molberg PJ, Hopkins RS, Paulson J, et al. Fatal incident risk factors in recreational boating in Ohio. Public Health Rep 1993;108:340-6.

72 Driscoll TR, Harrison JE, Steenkamp M. Alcohol and drowning in Australia. Inj Control Saf Promot 2004;11:175-81.

73 Hedberg K, Gunderson PD, Vargas C, et al. Drownings in Minnesota, 1980-85: a population-based study. Am J Public Health 1990;80:1071-4.

74 Lincoln JM, Perkins R, Melton F, et al. Drowning in Alaskan waters. Public Health Rep 1996;111:531-5.

75 Li GH, Baker SP. A comparison of injury death rates in China and the United States, 1986. Am J Public Health 1991;81:605-9. Research Support, U.S. Gov't, P.H.S.

76 Gomez DA, Saywell RM, Zollinger TW, et al. Factors related to adult drowning. J Safety Res 1992;23:1-8.

77 Claesson A, Druid H, Lindqvist J, et al. Cardiac disease and probable intent after drowning. Am J Emerg Med 2013;31:1073-7. 


\section{IP}

Epidemiology, risk factors and strategies for the prevention of global unintentional fatal drowning in people aged 50 years and older: a systematic review

Amy E Peden, Richard C Franklin and Ana Catarina Queiroga

Inj Prev published online August 3, 2017

Updated information and services can be found at:

http://injuryprevention.bmj.com/content/early/2017/08/03/injuryprev-

2017-042351

\section{These include:}

References This article cites 68 articles, 12 of which you can access for free at: http://injuryprevention.bmj.com/content/early/2017/08/03/injuryprev2017-042351\#ref-list-1

Email alerting service

Receive free email alerts when new articles cite this article. Sign up in the box at the top right corner of the online article.

\section{Notes}

To request permissions go to:

http://group.bmj.com/group/rights-licensing/permissions

To order reprints go to:

http://journals.bmj.com/cgi/reprintform

To subscribe to BMJ go to:

http://group.bmj.com/subscribe/ 